\title{
LACTOSYLCERAMIDE GALACTOSIDASE: COMPARISON WITH OTHER SPHINGOLIPID HYDROLASES IN DEVELOPING RAT BRAIN
}

\author{
NORMAN S. RADIN, LISELOTTE HOF*, ROY M. BRADLEY AND ROSCOE O. BRADY
}

Mental Health Research Institute**, University of Michigan, Ann Arbor, Mich. 48104 and Laboratory of Neurochemistry***, National Institute of Neurological Diseases, Bethesda, Md. 20014 (U.S.A.)

(Accepted February 1st, 1969)

\section{INTRODUCTION}

It is not yet clear whether lysosomal enzymes act only in degenerative processes, in response to noxious stimuli, or whether they act in the normal degradative processes of turnover. In support of the latter belief is the observation that specific lysosomal enzymes are absent (or highly deficient) in certain genetic lesions characterized by accumulation of the intermediates on which they act ${ }^{6,7,9,21,23}$. Another type of evidence comes from comparison of turnover rates and specific activities of lysosomal enzymes: hydrolases occurring in a tissue at relatively high levels should correlate with substances that undergo relatively high turnover. Still further evidence for normal functioning might come from comparisons of changes with age in level of substrate and hydrolase.

The last two approaches have been used in this and a preceding study ${ }^{4}$. It was shown that there is appreciable parallelism between the concentrations of galactosylceramide and the galactosidase which acts on it in the brains of developing rats. Ceramide hydrolase, on the other hand, follows a pattern more like that of ganglioside concentration. Ceramide appears to be an intermediate in the breakdown of both galactosylceramide and ganglioside, as well as sphingomyelin ${ }^{2,12,14}$. Since ganglioside has a somewhat higher turnover rate than galactosylceramide ${ }^{18,22}$, one might expect to find ceramide hydrolase following the developmental pattern of the former lipid.

Glucosylceramide and lactosylceramide ('lactoside') appear to be additional intermediates in the breakdown of ganglioside, so their hydrolases were examined in this study in an effort to extend the parallelism. By way of comparison, sphingomyelinase (a cholinephosphohydrolase) and galactosylphenol hydrolase were also determined. The latter is probably not a single enzyme but rather a conglomerate of $\beta$ galactosidases exhibiting activity toward phenolic galactosides. Evidence is presented

* Present address: Department of Pediatrics, The University of Chicago, Chicago, Ill. 60637 (U.S.A.).

** N.S. Radin.

*** R. M. Bradley and R. O. Brady. 
in this paper which indicates that much of the galactosylphenol hydrolase is actually lactosylceramide galactosidase.

METHODS

Preparation of ${ }^{3} \mathrm{H}$-labeled lactosylceramide

Crude ganglioside was prepared from pig brain by solvent partitioning between chloroform-methanol-water ( $8: 4: 3$, by vol.) followed by alkaline methanolysis ${ }^{18}$. The lipid was heated for $2 \mathrm{~h}$ at $90^{\circ} \mathrm{C}$ in $1 \mathrm{~N}$ sulfuric acid and the acid was neutralized at $0^{\circ} \mathrm{C}$ with gaseous ammonia. These hydrolytic conditions were found to give the best yield of lactosylceramide. The mixture was washed by partitioning as above and the lower layer was evaporated to dryness. Fractionation on a silica gel column ( $70 \mathrm{~g}$ of Unisil, Clarkson Chemical Co., Williamsport, Pa.) with chloroform-methanol (96:4) yielded ceramide plus glucosylceramide, and chloroform-methanol (90:10) yielded most of the lactosylceramide, contaminated with a little glucosylceramide. In this way about $185 \mathrm{mg}$ of lactoside were obtained from $1 \mathrm{~kg}$ of brain. The more polar glycolipids were eluted with chloroform-methanol $(3: 1)$ for further hydrolysis to increase the yield of lactosylceramide.

The lactosylceramide was made radioactive by a variation of a method previously applied to galactosylceramide ${ }^{14}$. Lactoside $(50 \mathrm{mg})$ was dissolved in $12 \mathrm{ml}$ of tetrahydrofuran, freshly distilled from $\mathrm{KOH}$ to remove interfering peroxides, and 12 $\mathrm{ml}$ of $10 \mathrm{~m} M$ potassium phosphate buffer $(\mathrm{pH} 7)$ were added. To this solution was added $1 \mathrm{ml}$ of galactose oxidase (AB Kabi, Stockholm, Sweden, $10^{6}$ units) and the mixture was shaken gently at $24^{\circ} \mathrm{C}$ for $4 \mathrm{~h}$. Additional oxidase was added $(0.5 \mathrm{ml})$, the shaking was continued overnight, and the mixture was partitioned with $25 \mathrm{ml}$ of chloroform-methanol $(4: 1)$. The upper layer was washed with $2 \times 15 \mathrm{ml}$ of the same mixture and the pooled lower layers were washed with $15 \mathrm{ml}$ of water-methanol (1:1). Analysis by thin-layer chromatography (TLC) of the oxidized lactoside using chloroform-methanol-water (24:7:1) showed one major spot, moving just ahead of some remaining unoxidized lactoside, together with a trace of contaminating glucosylceramide.

The solids obtained from this solution were dissolved in peroxide-free tetrahydrofuran $(5 \mathrm{ml})$ with the aid of heat. To this was added $0.35 \mathrm{ml}$ of $\left.{ }^{3} \mathrm{H}\right] \mathrm{NaBH}_{4}$ in $1 \mathrm{mM} \mathrm{NaOH}(6 \mathrm{mC}, 1 \mathrm{mg})$ and the mixture was left overnight. To complete the reduction $10 \mathrm{mg}$ of non-radioactive $\mathrm{NaBH}_{4}$ were added and left $1 \mathrm{~h}$. Recovery of labeled lactoside was accomplished by adding $7 \mathrm{ml}$ of $1 \mathrm{~N}$ acetic acid and $25 \mathrm{ml}$ of chloroform-methanol $(2: 1)$; the lower layer from this system was washed with $7 \times$ $15 \mathrm{ml}$ of methanol-water $(1: 1)$, each wash containing $15 \mathrm{mg} \mathrm{NaCl}$. The lactosylceramide was purified in $3 \mathrm{mg}$ portions by TLC on $0.5 \mathrm{~mm}$ layers of Silica Gel H (Brinkmann), using chloroform-methanol-water $(24: 7: 1)$. The band was located by spraying methanol-water $(1: 1)$, the powder was scraped off, and the lactoside was eluted with chloroform-methanol-water $(7: 7: 1)$ by grinding the powder with the solvent in a mortar and transferring it to a column for further elution. Traces of silica 
were removed by solvent partitioning. The yield was $31 \mathrm{mg}$, with specific activity of 10,000 counts $/ \mathrm{min} / \mathrm{nmole}$ (calculated for a mol. wt. of 890 ). Only $4.6 \%$ of the activity applied to the TLC plate was found outside the main band. The lipid was counted in anhydrous XDC solution ${ }^{10}$.

The conditions for preparing the labeled lactoside were not investigated, and it is very likely that a higher specific activity could have been achieved with more labeled borohydride. Lactose ${ }^{1}$ and lactosylceramide (B. W. Agranoff and W. D. Suomi, personal communication) are oxidized very slowly by galactose oxidase but, by using a relatively concentrated solution of oxidase and lactoside, we were able to obtain a satisfactory yield of aldehyde. Carrier was added to the labeled lactoside to give a specific activity of 250 counts $/ \mathrm{min} / \mathrm{nmole}$.

Analysis by gas-liquid chromatography of a sample of lactoside purified by TLC showed the presence only of the fatty acids typical of gangliosides ${ }^{20}: 9.1 \%$ arachidic acid, $90.6 \%$ stearic acid, and $0.3 \%$ palmitic acid. The distribution is distorted, showing a low content of palmitate and high content of arachidate, apparently as the result of the chromatographic steps involved.

\section{Enzyme assay procedures}

The brains were removed from rats anesthetized with carbon dioxide and decapitated, then were homogenized in 6 vol. of Tris buffer-Mg-mercaptoethanol and sonicated as in the previous study ${ }^{4}$. The homogenates were stored at $-20^{\circ} \mathrm{C}$ prior to assay.

Assay for lactosylceramide galactosidase activity was carried out by thawing the brain suspension at room temperature, diluting 10 -fold with water, and incubating with labeled lactoside under conditions similar to those used by Gatt and Rapport ${ }^{13}$. A chloroform-methanol solution of lactoside (200 nmoles) and Triton X-100 (0.5 mg) was evaporated to dryness in a test tube and the residue emulsified in $0.4 \mathrm{ml}$ of $0.5 \%$ sodium taurocholate solution. The taurocholate was a crude preparation from Mann Research Laboratories, New York, N.Y. Heating and sonicating the mixture in a bath of the type used for cleaning speeded the emulsification step. To the clear dispersion was added $0.2 \mathrm{ml}$ of $2 M$ sodium acetate buffer ( $\mathrm{pH} 5.0$ at room temperature), water, and $0.21 \mathrm{ml}$ or $0.105 \mathrm{ml}$ of brain suspension ( 3 or $1.5 \mathrm{mg}$ tissue); total volume = $1 \mathrm{ml}$. The tubes were shaken $2 \mathrm{~h}$ at $37^{\circ} \mathrm{C}$ and the liberated $\left[{ }^{3} \mathrm{H}\right]$ galactose separated from the substrate by a previously described procedure ${ }^{4}$ The dry ${ }^{3} \mathrm{H} /$ galactose (plus buffer, etc.) was dissolved in $0.5 \mathrm{ml}$ water and $1 \mathrm{ml}$ of BBS-3 (a solubilizing agent from Beckman Instruments) and $10 \mathrm{ml}$ of toluene-based scintillation solution were added; the faintly cloudy mixture was allowed to stand briefly at room temperature to clear before counting. This counting system gave much greater counting efficiency than the previously used XDC mixture. Blanks with incubated substrate but no enzyme corresponded to an activity of about $0.2 \mathrm{nmole} / \mathrm{h}$.

Glucocerebrosidase and sphingomyelinase activities were determined using ${ }^{14} \mathrm{C}$ labeled sphingolipids synthesized according to previously published procedures ${ }^{8,17}$. For the former, $50 \mu \mathrm{l}$ portions of homogenate, $15 \mu \mathrm{l}$ of potassium phosphate buffer 
( $\mathrm{pH} 6.0$ ), $125 \mathrm{nmoles}$ of glucocerebroside (550 counts/min/nmole), $0.6 \mathrm{mg}$ of sodium cholate, $0.2 \mathrm{mg}$ of Cutscum (Fisher Chemical Co.) and water in a final volume of 150 $\mu \mathrm{l}$ were incubated for $1 \mathrm{~h}$ at $37^{\circ} \mathrm{C}$. Sphingomyelinase activity was determined by incubating $25 \mu \mathrm{l}$ of homogenate with 67 nmoles of sphingomyelin (347 counts/min/ nmole), $25 \mu$ l of $1 M$ potassium acetate buffer ( $\mathrm{pH} 5.0$ ), $0.25 \mathrm{mg}$ of sodium cholate, and water as above. The amount of labeled substrate hydrolyzed was determined as described previously ${ }^{17}$. The extent of hydrolysis is proportional to the amount of protein in homogenate preparations of various tissues under these conditions ${ }^{25}$. Galactosylphenol hydrolase activity was determined as described before ${ }^{14}$, using $p$-nitrophenyl $\beta$-D-galactoside as substrate.

\section{The dispersibility of lactosy/ceramide and galactosylphenol galactosidases}

For further comparison of these enzymes, additional rat brains were analyzed to find how much enzyme was present in the cytosol (highspeed supernatant) and how much of the particulate enzyme could be dispersed by sonication. The schedule used for homogenization, sonication, and centrifugation was as previously described ${ }^{4}$, but here the particulate fractions were suspended in $20 \mathrm{mM}$ Tris, $\mathrm{pH} 7.4$, instead of TrisMg-mercaptoethanol. The Tris buffer was also added to the cytosol fraction. Four rat brains were pooled for each determination; 3 groups of rats were run for each age point. The rats used were females of the Sprague-Dawley strain from Spartan Laboratories, Haslett, Mich. They were kept 3 days in our animal quarters before sacrifice.

\section{RESULTS}

\section{Properties of the lactoside galactosidase}

As reported by Gatt and Rapport for a partially purified preparation of the enzyme ${ }^{13}$, taurocholate was needed for activity but higher levels of bile salt resulted in lower activity. Our brain homogenates showed optimal activity with $2 \mathrm{mg} / \mathrm{ml}$ of taurocholate, which was the minimal amount needed to give a clear dispersion of the substrate. Triton X-100, in our hands, did not increase the observed activity, but did speed the process of dispersing the substrate. Galactosylceramide galactosidase is stimulated appreciably by oleic acid ${ }^{4}$, but lactosylceramide galactosidase is inhibited slightly ( $20 \%$ with 0.25 or $1 \mathrm{mg}$ of oleate). Gatt and Rapport ${ }^{13}$ found a much higher inhibition with palmitate, which may be due to the use of much less protein in their assay rather than the difference in fatty acid. Like these workers, we found $\gamma$-galactonolactone to be a good inhibitor ( $80 \%$ with $2.5 \mathrm{mM}$ lactone). $p$-Nitrophenyl $\beta$-Dthiogalactoside ( $5 \mathrm{~m} M$, Cyclo Chemical Corp., Los Angeles, Calif.) inhibited the lactoside galactosidase $36 \%$, but was not itself a substrate. The rate of lactoside hydrolysis proved to be linear for at least $2 \mathrm{~h}$ in our system and proportional to the quantity of brain tissue up to $3 \mathrm{mg}$ per incubation tube.

Changes in hydrolase activities with age (Fig. 1)

There was a $50 \%$ increase in lactosylceramide galactosidase activity between 


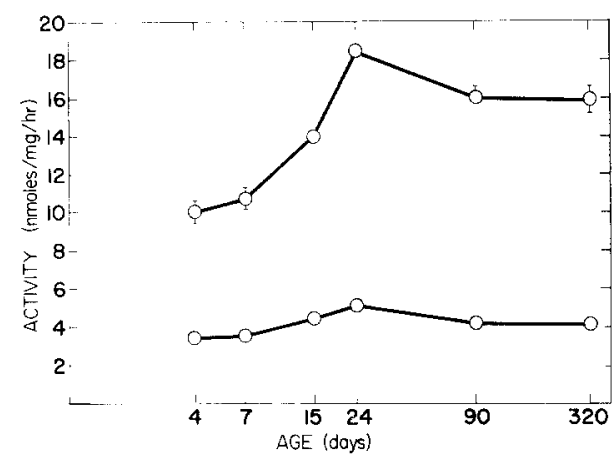

Fig. 1. Changes with age in galactosidase activities of rat brain. Lower curve, lactosylceramide galactosidase. Upper curve, galactosylphenol galactosidase. The oldest rats were actually 9-12 months old. The average values for three separate series of rats were used for plotting the curves, and the values of the two extremes within each age group are shown by the upper and lower tips of the vertical lines (where the divergence was greater than the radius of the circle).

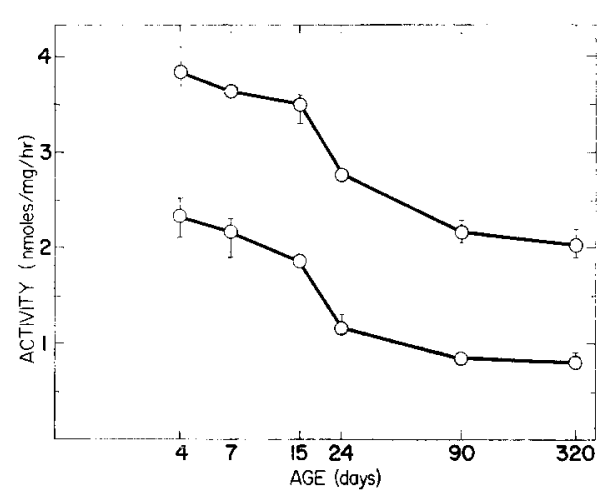

Fig. 2. Changes with age in rat brain sphingolipid hydrolases. Lower curve, sphingomyelin phosphocholine hydrolase. Upper curve, glucosylceramide glucosidase.

the 4th and 24th days, followed by a partial restoration to the starting activity and then a leveling off. The galactosylphenol galactosidase activity showed a similar course, but the initial rise was about $85 \%$ and the decline was smaller. This curve matches well the curve previously observed with the same substrate ${ }^{4}$. At the age of peak activity, the brain's activity toward the artificial substrate was 3.6 times as great as toward the natural substrate.

The hydrolases acting on glucosylceramide and sphingomyelin (Fig. 2) showed a marked similarity to one another, but differed greatly from the galactosidases. The activities decreased with increasing age, most rapidly between 15 and 24 days. There is some resemblance to the changes observed previously for glucosylphenol hydrolase ${ }^{4}$; this activity showed a slight rise between 4 and 15 days, then declined appreciably.

\section{Dispersibility of galactosidases}

Table I lists the proportion of each enzyme activity in the cytosol, dispersible, and non-dispersible fractions. There is a marked parallelism in the distributions at 


\section{TABLE I}

STATES OF DISPERSION OF LACTOSYLCERAMIDE AND GALACTOSYLPHENOL HYDROLASES AS A WINCTION. OF AGE IN RAT BRAIN

The values shown are percents of total brain activity. Those in italics are averages of three values, shown below each number in parentheses. The rats listed as 320 days old are actually $9-12$ months old

\begin{tabular}{|c|c|c|c|c|c|c|}
\hline \multirow{2}{*}{$\begin{array}{l}\text { Age } \\
\text { (days) }\end{array}$} & \multicolumn{2}{|c|}{ Lactoside hydrolase } & \multirow[b]{2}{*}{ Non-dispersible } & \multicolumn{3}{|c|}{ Nitrophenyl galactoside hydrolase } \\
\hline & Cytosol & Dispersible & & Cytosol & Dispersible & Non-dispersible \\
\hline 5 & $\begin{array}{c}8 \\
(4,6,13)\end{array}$ & $\begin{array}{l}73 \\
(76,73,70)\end{array}$ & $\begin{array}{l}19 \\
(20,21,16)\end{array}$ & $\begin{array}{c}5 \\
(5,7,4)\end{array}$ & $\begin{array}{l}76 \\
(74,78,76)\end{array}$ & $\begin{array}{l}19 \\
(22,14,20)\end{array}$ \\
\hline 15 & $\begin{array}{c}6 \\
(4,3,11)\end{array}$ & $\begin{array}{l}74 \\
(79,72,71)\end{array}$ & $\begin{array}{l}20 \\
(17,25,18)\end{array}$ & $\begin{array}{c}3 \\
(3,3,3)\end{array}$ & $\begin{array}{l}77 \\
(75,81,76)\end{array}$ & $\begin{array}{l}19 \\
(21,16,21)\end{array}$ \\
\hline 320 & $\begin{array}{l}12 \\
(13,10,14)\end{array}$ & $\begin{array}{l}68 \\
(75,67,63)\end{array}$ & $\begin{array}{l}19 \\
(12,23,22)\end{array}$ & $\begin{array}{l}10 \\
(13,11,6)\end{array}$ & $\begin{array}{l}74 \\
(73,79,69)\end{array}$ & $\begin{array}{l}16 \\
(14,10,25)\end{array}$ \\
\hline
\end{tabular}

each age for the two activities. Nearly all the activity was in particles after homogenization of the brain and most of the activity was rendered 'soluble' by sonication. The only effect of age seems to be rise in older rats in the proportion found in the cytosol. Such a rise was noted also for galactosylceramide galactosidase and aryl sulfatase ${ }^{4}$.

\section{DISCUSSION}

\section{Galactosidase specificity}

Both Fig. 1 and Table 1 show great similarity with respect to age changes in total activity and dispersibility of lactosylceramide and galactosylphenol hydrolases. This suggests that the unnatural substrate is hydrolyzed primarily by lactosylceramide galactosidase rather than by other brain galactosidases. This interpretation is supported by previous work showing considerable separation of galactosylphenol hydrolase from galactosylceramide hydrolase by physical means ${ }^{3}$, as well as markedly different patterns of age change and dispersibility ${ }^{4}$. Two additional galactosidases have been purified from brain, active toward galactosylphenols but not toward lactosylceramide or galactosyllactosylceramide ${ }^{15}$. It is known that galactosidase activity is present in brain toward the above-mentioned trihexoside ${ }^{5}$, ganglioside $\mathrm{G}_{\mathrm{M} 1}$, and asialo- $\mathrm{G}_{\mathrm{M} 1}{ }^{12}$, but there are no data for the extent of the contributions of these activities toward galactosylphenol hydrolysis.

Patients suffering from the genetic defect, $\mathrm{G}_{\mathrm{M} 1 \text {-gangliosidosis; accumulate }}$ ganglioside $G_{M 1}$, asialo- $G_{M 1}$, and lactosylceramide in their brains ${ }^{24}$. Their tissues exhibit a great deficiency in galactosylphenol hydrolase and the galactosidase which acts on $\mathrm{G}_{\mathrm{M}} \mathrm{I}^{21}$. If the disease is the result of the lack of a single enzyme, it is reasonable to conclude that only one galactosidase acts on the above three galactosides occurring as intermediates in ganglioside catabolism, and that this enzyme accounts for most of the galactosylphenol hydrolase activity observed in brain. 


\section{The role of lysosomal enzymes in turnover}

Galactosylceramide galactosidase exhibits a considerable rise in activity during the early stages of myelination, reaching a peak at roughly 90 days, then declining slightly ${ }^{4}$. This can be compared with the rapid rise in concentration of galactosylceramide during the first 90 days or so and gradual leveling off in later months ${ }^{19}$. In contrast, ganglioside concentration rises more gradually, starting before birth in the rat and dropping slowly after about 21 days. The curve for lactosylceramide galactosidase (Fig. 1) seems to parallel that for the concentration of ganglioside. The curve for ceramidase reaches its peak at about 15 days but the decrease between 15 and 24 days is not great, so it parallels the other two curves reasonably well. The ratio of the specific activities of the two galactosidases acting on galactosylceramide and lactosylceramide, at their maximal values, is $1: 5$. This is consistent with the fact that galactosylceramide has a somewhat slower turnover rate than ganglioside. These relationships may mean that lysosomal hydrolases are constantly and normally acting on cell constituents, even in relatively mature brain.

The changes with age in glucosylceramide and sphingomyelin hydrolases show a somewhat different course. In the case of sphingomyelin concentration in rat brain ${ }^{11}$, there is a general rising trend until about 50 days, then a leveling off. These enzymes thus do not fit the above hypothesis. Nevertheless, it is possible that their high activities during early development reflect an unusually high turnover rate for sphingomyelin and glucosylceramide, which may be particularly active in the rapidly proliferating or developing cells characteristic of very young brains. Some support for this hypothesis may be seen in the increased activity of both enzymes in leukemic leucocytes compared to normal, mature circulating leucocytes ${ }^{16}$. (Galactosylceramide galactosidase is similar in both types of leucocytes.)

\section{SUMMARY}

Four enzyme assays were carried out with brains from rats of age 4 days to about 320 days. The enzymes were acid hydrolases: lactosylceramide galactosidase, galactosylphenol galactosidase, glucosylceramide glucosidase, and sphingomyelin phosphocholine hydrolase. The first two activities (based on wet brain weight) rose with age until about 24 days, then declined moderately; this curve parallels somewhat the curve for ganglioside concentration in brain. It is suggested that this parallelism supports the idea that lysosomal enzymes function in normal turnover. The other two enzymes studied showed a steadily declining activity with increasing age. It was found that the brain cytosol contained $12 \%$ or less of the galactosidase activities, the value increasing somewhat in older rats. Most of the particulate galactosidase activities could be dispersed by sonication. The similarities between the two galactosidase activities suggest that most of the hydrolysis of the galactosylphenol is carried out by the lactosylceramide hydrolase. A procedure is given for preparing $\left[{ }^{3} \mathbf{H}\right]$ lactosylceramide labeled in the galactose portion of the molecule and for the assay of its hydrolase. 


\section{ACKNOWLEDGEMENTS}

This work was supported by a grant from N.I.H. (NB 03192). We are indebted to Dr. Lars Svennerholm for telling us of the availability of excellent galactose oxidase from AB Kabi, and for Dr. Bernard Agranoff for details of its use in oxidizing lipid galactosides.

\section{REFERENCES}

1 Avigad, G., Amaral, D., Asensio, C., And Horecker, B. L., The d-galactose oxidase of Poly. porus circinatus, J. biol. Chem., 237 (1962) 2736-2743.

2 Barnholz, Y., Roltman, A., AND GatT, S., Hydrolysis of sphingomyelin by an enzyme from rat brain, J. biol. Chem., 241 (1966) 3731-3737.

3 Bowen, D. M., ANd Radin, N. S., Purification of cerebroside galactosidase from rat brain, Biochin. biophys. Acta (Amst.), 152 (1968) 587-598.

4 Bowen, D. M., AND RAdin, N. S., Cerebroside galactosidase : a method for determination and a comparison with other lysosomal enzymes in developing rat brain, J. Neurochem, 16 (1969) $501-512$

5 Brady, R. O., Gal, A. E., Bradlfy, R. M., and Martensson, E., Purification and properties of an enzyme that cleaves the terminal galactose molecule of galactosylgalactosylglucosylceramide, $J$. biol. Chem., 242 (1967) 1021-1026.

6 Brady, R. O., Gal, A. E., Bradley, R. M., Martensson, E., Warshaw, A. L., and Laster, L. Enzymatic defect in Fabry's disease : ceramide trihexosidase deficiency, New Engl. J. Med., 276 (1967) 1021-1026.

7 Brady, R. O., Kanfer, J. N., Mock, M. B., and Fredrickson, D. S., Evidence of an enzymatic deficiency in Niemann-Pick disease, Proc. nat. Acad. Sci. (Wash.), 55 (1966) 366-369.

8 Brady, R. O., Kanfer, J., and Shapiro, D., Purification and properties of a glucocerebrosidecleaving enzyme from spleen tissue, J. biol. Chem., 240 (1965) 39-43.

9 Brady, R. O., Kanfer, J. N., Shapiro, D., and Bradley, R. M., Demonstration of a deficiency of glucocerebroside-cleaving enzyme in Gaucher's disease, $J$. clin. Invest., 45 (1966) 1112-1115.

10 Bruno, G. A., and Christian, J. E., Determination of carbon-14 in aqueous bicarbonate solutions by liquid scintillation counting techniques, Anal. Chem., 33 (1961) 1216-1218.

11 Cuzner, M. L., And Davison, A. N., The lipid composition of rat brain myelin and subcellular fractions during development, Biochem. J., 106 (1968) 29-34.

12 GATT, S., Hydrolysis of monosialoganglioside and hexosylceramides by rat brain $\beta$-galactosidase, Biochim. biophys. Acta (Amst.), 137 (1967) 192-195.

13 GATt, S., AND RAPPORT, M. M., Hydrolysis of ceramide lactoside by an enzyme from rat brain, Biochem. J., 101 (1966) 680-686.

14 Hajra, A. K., Bowen, D. M., Kishimoto, Y., and Radin, N. S., Cerebroside galactosidase of brain, J. Lipid Res., 7 (1966) 379-386.

15 Jungalwala, F. B., AND Robins, E., Separation, purification, and substrate specificities of $\beta$. galactosidases and $\beta$-glucuronidase from brain, $J$. biol. Chem., 243 (1968) 4258-4266.

16 Kampine, J. P., Brady, R. O., Yankee, R. A., Kanfer, J. N., Shapiro, D., and Gal, A. E., Sphingolipid metabolism in leukemic leucocytes, Cancer Res., 27 (1967) 1312-1315.

17 Kanfer, J. N., Young, O. M., Shapiro, D., and Brady, R. O., Purification and properties of a sphingomyelin-cleaving enzyme from rat liver tissue, J. biol. Chem., 241 (1966) 1081-1084.

18 KISHImoto, Y., DAvies, W. E., AND RADIN, N. S., Turnover of the fatty acids of rat brain gangliosides, glycerophosphatides, cerebrosides, and sulfatides as a function of age, J. Lipid Res., 6 (1965) 525-531.

19 Kishimoto, Y., Davies, W. E., AND Radin, N. S., Developing rat brain: changes in cholesterol, galactolipids, and the individual fatty acids of gangliosides and glycerophosphatides, $J$. Lipid Res., 6 (1965) 532-536.

20 KISHImoto, Y., AND RAdIN, N. S., Determination of brain gangliosides by determination of ganglioside stearic acid, J. Lipid Res., 7 (1966) 141-145.

21 OKADA, S., AND O'BrIEN, J. S., Generalized gangliosidosis: beta-galactosidase deficiency, Science, $160(1968) 1002-1004$. 
22 Radin, N. S., Martin, F. B., AND Brown, J. R., Galactolipide metabolism, J. biol. Chem., 224 (1957) 499--507.

23 Sandhoff, K., Andreae, U., and Jatzkewitz, H., Deficient hexosaminidase activity in an exceptional case of Tay-Sachs disease with additional storage of kidney globoside in visceral organs, Life Sci., 7 (1968) 283-288.

24 Suzuki, K., And Chen, G. C., Brain ceramide hexosides in Tay-Sachs disease and generalized gangliosidosis (GM1-gangliosidosis), J. Lipid Res., 8 (1967) 105-113.

25 Weinreb, N. J., Brady, R. O., AND TAPPEL, A. L., The lysosomal localization of sphingolipid hydrolases, Biochim. biophys. Acta (Amst.), 159 (1968) 141-146. 